\title{
Court Interpreters View of Language Use in Subordinate Courts in Nyanza Province, Kenya
}

\author{
Kenneth Odhiambo \\ The University of Kabianga, Kenya \\ Claris Kasamba Kavulani \\ The University of Kabianga, Kenya \\ Peter Maina Matu \\ Technical University of Kenya, Kenya
}

\begin{abstract}
This paper presents the views of the court interpreters about language use in courts in Kenya. Kenya is a multilingual country with over 42 languages. In such a heterogeneous society, language issues in official communication become intricate as those who do not understand the languages designated as official are discriminated against. In the legal sphere, the policy is that English and Kiswahili are the official languages of courtroom communication while interpreters are provided for those who do not understand English. Hence the courts are multilingual in nature and it is against this background of the use of various languages that this paper examines the views of the court interpreter on the various languages used in courtroom communication. A survey design was used in this study. The study population comprised court interpreters from selected subordinate courts in Nyanza province, Kenya. Purposive sampling was used to select the court interpreters. Data for the study was generated through questionnaire administered to the court interpreters.
\end{abstract}

Index Terms — subordinate courts, court interpreters, language use, Dholuo, Kenya

\section{INTRODUCTION}

Kenya is a multilingual country with over 42 languages with two official languages (Mbaabu, 1996). In the legal sphere, to entrench the use of English, the Criminal Procedure Code CAP 75 (1987) declares English as the official language of the High Court and a provision for interpreters for litigants who do not speak and understand English. The language of the Lower Court is either English or Kiswahili, depending on the linguistic setting and the linguistic competence of the judicial officers. In addition, the law provides that the litigants be informed of the charge against them in a language they understand and speak. This means that Kenyan courts are bilingual or to be exact multilingual. Hence inequality in our courts is created by linguistic diversity that is supposed to reduce inequality and where a dialogue involves persons of unequal linguistic efficiency, injustice is likely to result. Therefore, the litigants who do not speak and understand English are excluded from the discourse in court, even if they have competent representation from a lawyer. They therefore lose the right to participate in a trial, which concerns them directly except in the presence of an interpreter.

This means that when an advocate or prosecutor communicates with a non-English speaking litigant, it must be by means of an interpreter which implies that the interpreter must be able to communicate adequately in both English, when speaking to an English speaking litigant and in the other language, when speaking to a non-English speaking litigant. In the legal setting, linguistic competence of the interpreter in both languages must therefore include a strong command of legal vocabulary and the equivalence (or non-equivalence) of terms and concepts across languages (Gonzalez, Vasquez and Mikkelson, 1991). Otherwise the aim of providing unimpeded access to legal services will be compromised.

For an average person, confrontation with the criminal justice system is a frightening experience as most people enter the courtroom with little or no knowledge of courtroom procedure or language. The situation is exacerbated when the court actors are speaking in a language that the litigants do not understand totally or do not understand well. This is often the case for people who stand accused in Kenyan courts where the majority of the litigants do not speak the language of the courts (Kinyanjui, 2000).

Research conducted on bilingual discourse suggests that language barriers are often identified as the most frequent impediment to legal discourse (Berk-Seligson, 1990;Gonzalez, Vasquez and Mikkelson, 2000; Mikkelson, 1998). This is in addition to the various strategies that the advocates employ in questioning (Penman, 1990). A legal discourse encounter relies primarily on verbal communication and various strategies may be employed to achieve this. The use of interpreters is therefore recommended when the advocate-litigant communication is limited by language difficulties.

Language Use in Courts in Kenya 
In the Kenyan legal system, English is used as the official language of communication. The Judicature Act Cap 8, Section 194 (4) of the Criminal Procedure Code, and Section 86 (1) of the Criminal Procedure Act, state that English shall be the official language of communication in the country's courts. The courts thus assume monolingualism, and hence when dealing with litigants who do not understand English, interpretation is provided for.

As English is the language of courtroom communication, this study is cognizant of the fact that it is also the language of training for the advocates, magistrates and prosecutors, who encounter non-English speaking litigants. The nonEnglish speaking litigants are disadvantaged and to make sure they effectively participate in their trials, interpreters are provided for.

With English as the official language of courtroom communication, the language of court records will normally be English. Hence the magistrate will heavily rely on the interpreter's efficiency in the process of interpretation to keep an accurate record of the proceedings. The litigants who do not speak English have a right not only to understand the charges against them and the court proceedings, but also to a trial that is substantially in their own language. The right to use a language that one is well versed in should therefore not be regarded as conditional on the litigant. It therefore requires the court to accommodate the litigants' preference to use their own language. This paper seeks to establish language use in Kenyan courts through the eyes of the court interpreter in light of language use in selected subordinate courts in Nyanza province, Kenya.

\section{METHODOLOGY}

The aim of this paper is to present the views of court interpreters towards language use in subordinate courts in Nyanza Province. A survey design was used in this study and the data used were procured from the responses provided by the interpreters to the closed-ended questions in a questionnaire. The population of this study comprises of interpreters from selected courts in Nyanza province. The choice of the courts is informed by the fact that the residents in these districts are functionally bilinguals but with very strong affinity to their mother tongue (Dholuo). This means that they will tend to use Dholuo in courtroom communication and hence use the services of an interpreter. The research area in this study is drawn from the subordinate courts in Nyanza Province of Kenya. Nyanza Province is one of the eight (8) provinces in Kenya which include Nairobi, Western, Rift Valley, Eastern, Central, Coast and North Eastern. Nyanza Province had eleven Districts at the time this research was being carried out. The districts are: Kisii Central, Kisii North, Kisii South, Kuria, Migori, Homabay, Rachuonyo, Nyando, Kisumu, Siaya, and Bondo.

In analyzing the data from the questionnaires, descriptive statistics are used. The organized data showed what the responses to the statements in the questionnaires were in frequencies and percentages. The descriptive statistics were provided through frequency distribution tables, which gave information on how common certain phenomena were. Due to this, it was relatively simple to determine the demographic information and language use in court.

The statistics generated by SPSS provided the researcher with the following ways of tabulating the results: Frequency distribution tables and Percentages.

A total of 10 questionnaires were distributed to the interpreters operating in selected subordinate courts in Nyanza Province. The return rate was $100 \%$. The background data of the samples of the interpreters are discussed here in Tables 1- 7. Note that in some cases the interpreters left certain categories blank and these were recorded as missing values.

\section{RESULTS AND DISCUSSION}

This section presents an analysis of the data collected during the field work conducted in selected subordinate courts in Nyanza Province. This section highlights the results based on the responses provided in the interpreters' questionnaire. The items in this questionnaire provided for self-evaluation in answering the items The discussion in this section comprises four sections: the first section presents an overview of the general and linguistic characteristics of the interpreters; the second section highlights the language use profile in court, which will specifically highlight: the rate of proficiency of the interpreters in English, Kiswahili and Dholuo, language combination proficiency, and languages interpreters frequently use in court. It will also deal with the language frequently used by litigants in court, and the preferred language interpreters use with legal professionals in court.

The background information of the respondents in terms of gender, age, mother tongue, other languages spoken, level of education, experience, and formal training as interpreter revealed the following information about the interpreters.

\section{General and linguistic characteristics of the respondents}

The general and linguistic characteristics of the interpreters include age, gender, mother-tongue, other languages spoken, education level, length of service as an interpreter and formal interpreter training.

Gender: There were only two female and eight male respondents who participated in the study. Gender was unlikely to skew the results of the study as no item in the questionnaire was considered gender sensitive. The results of gender are shown in Table 1. 
TABLE 1:

GENDER

\begin{tabular}{|l|l|l|}
\hline Gender & Frequency & Percentage \\
\hline Male & 8 & $80 \%$ \\
\hline Female & 2 & $20 \%$ \\
\hline Total & 10 & $100 \%$ \\
\hline
\end{tabular}

Age: $60 \%$ of the interpreters who participated in the study were aged between 30 and 35 and they were the majority. A total of $30 \%$ were in their twenties. The data also showed that the youngest interpreter was 27 and the oldest was 45 years. This information is shown in Table 2.

TABLE 2:

AGE

\begin{tabular}{|l|l|l|}
\hline Age & Frequency & Percentage \\
\hline 27 & 1 & $11 \%$ \\
\hline 29 & 2 & $22 \%$ \\
\hline 30 & 2 & $22 \%$ \\
\hline 32 & 2 & $22 \%$ \\
\hline 34 & 1 & $11 \%$ \\
\hline 35 & 1 & $11 \%$ \\
\hline 45 & 1 & $11 \%$ \\
\hline Total & 10 & $100 \%$ \\
\hline
\end{tabular}

Mother-tongue: A hundred percent (100\%) of the respondents indicated that their mother-tongue was Dholuo. This is accounted for by the fact that the respondents were purposively sampled for in the study and the region of the study is predominantly inhabited by speakers of Dholuo. This is shown in Table 3.

TABLE 3:

MOTHER-TONGUE

\begin{tabular}{|l|l|l|}
\hline Mother-tongue & Frequency & Percentage \\
\hline Dholuo & 10 & $100 \%$ \\
\hline Total & 10 & $100 \%$ \\
\hline
\end{tabular}

Other languages spoken: The interpreters were asked to indicate other languages that they spoke. The idea of other languages implies the other languages that interpreters spoke in addition to mother tongue. All of them cited English and Kiswahili as the other language that they spoke. The fact that all the interpreters cited English and Kiswahili pointed towards the fact that the language policy in the subordinate courts required the use of either English and Kiswahili as alternative languages. In addition, English and Kiswahili are taught in schools it therefore follows that since these interpreters were educated at least up to form 4 level they must have been exposed to English and Kiswahili. This is shown in Table 4.

TABLE 4:

OTHER LANGUAGES SPOKEN

\begin{tabular}{|l|l|l|}
\hline Language & Frequency & Percent \\
\hline English & 10 & $100 \%$ \\
\hline Kiswahili & 10 & $100 \%$ \\
\hline
\end{tabular}

Education Level: All the interpreters in this study had attained form four level of education. This was a very important variable because for one to be employed as interpreter one must have at least form four level of education. Out of the interpreters who answered the questionnaire $60 \%$ reported that they had attended post-secondary school colleges. The reported college level education courses were courses that were not relevant to their work as interpreters. This information is shown in Table 5.

TABLE 5:

EDUCATION LEVEL

\begin{tabular}{|l|l|l|}
\hline Level & Frequency & Percent \\
\hline Secondary & 4 & $40 \%$ \\
\hline College & 6 & $60 \%$ \\
\hline Total & 10 & $100 \%$ \\
\hline
\end{tabular}

Length of service as an interpreter: As shown in Table 6 the interpreters had varied number of years in their service as interpreters. The interpreter with the shortest service period was 1 year and the interpreter with the longest service period was 9 years. The others ranged from 4 years to 8 years of service. 
TABLE 6:

LENGTH OF SERVICE

\begin{tabular}{|l|l|l|}
\hline Years & Frequency & Percentage \\
\hline 1 & 1 & $10 \%$ \\
\hline 4 & 1 & $10 \%$ \\
\hline 5 & 2 & $20 \%$ \\
\hline 6 & 2 & $20 \%$ \\
\hline 7 & 1 & $10 \%$ \\
\hline 8 & 1 & $10 \%$ \\
\hline 9 & 1 & $10 \%$ \\
\hline Missing value & 1 & $10 \%$ \\
\hline Total & 10 & $100 \%$ \\
\hline
\end{tabular}

Formal interpreter training: In order to establish whether the interpreters had received formal training in interpretation, the interpreters were asked whether they had undergone any formal training as interpreters. $10 \%$ reported that they had been trained, $80 \%$ reported that they had not been trained while $10 \%$ did not answer this item. In terms of training even the $10 \%$ who reported that they had been trained placed a rider that the training was not court interpreter training but sign-language interpreter training.

The lack of training of the court interpreters is an indication that many litigants who come to court use the services of untrained interpreters. This further indicates the need for training of the court interpreters. One means of addressing the barriers facing people who do not understand the language of the court in participating in the justice system is to provide professional development for the court interpreters. This is shown in Table 7.

TABLE 7:

FORMAL INTERPRETER TRAINING

\begin{tabular}{|l|l|l|}
\hline Response & Frequency & Percentage \\
\hline Yes & 1 & $10 \%$ \\
\hline No & 8 & $80 \%$ \\
\hline Missing Value & 1 & $10 \%$ \\
\hline Total & 10 & $100 \%$ \\
\hline
\end{tabular}

Based on the background information presented in Tables 1-7, some conclusions can be arrived at about the interpreters. Firstly, all the interpreters are multilingual. This is due to the fact that they speak Dholuo as their mothertongue as well as English and Kiswahili being languages that they learned at school. These three languages are also the working languages in the subordinate court where the data was collected. The second conclusion one can arrive at is that all the interpreters have had a minimum of 12 years of education. This is based on the statistics derived from Table 5 which indicates that all of the interpreters have had secondary education with $60 \%$ of them furthering their education up to college level. The third conclusion is that the interpreters reported that they have had no formal training in interpretation and thus there is a need for interpreter training programme. It is important at this point to note that the research did not delve into actual interpreter training but dealt with issues of training as reported by the interpreters.

The previous section has dealt with the background of the interpreters. This section deals with language related issues in court. Specifically, it deals with individual language proficiency rating of the interpreters, language combination proficiency rating, languages frequently used in court by the interpreters, languages frequently used by litigants and languages the interpreters use with legal professionals in court.

The interpreters were asked to state their proficiency in the use of Kiswahili, English and Dholuo as individual languages. The notion of proficiency was pre-coded on the questionnaire under four categories namely: EXCELLENT, GOOD, AVERAGE, and POOR. Table 8 shows the self-rated proficiency of the interpreters.

TABLE 8:

RATE OF PROFICIENCY IN INDIVIDUAL LANGUAGES

\begin{tabular}{|c|c|c|c|c|c|c|c|c|}
\hline & \multicolumn{8}{|c|}{ RATE OF PROFICIENCY IN INDIVIDUAL LANGUAGES } \\
\hline & \multicolumn{8}{|c|}{ ( } \\
\hline & \multicolumn{2}{|c|}{ Excellent } & \multicolumn{2}{|l|}{ Good } & \multicolumn{2}{|c|}{ Average } & \multicolumn{2}{|l|}{ Poor } \\
\hline Language & Freq & Per & Freq & Per & Freq & Per & Freq & Per \\
\hline English & - & - & 8 & $80 \%$ & 2 & $20 \%$ & - & - \\
\hline Kiswahili & 1 & $10 \%$ & 6 & $60 \%$ & 3 & $30 \%$ & - & - \\
\hline Dholuo & 4 & $40 \%$ & 6 & $60 \%$ & - & - & - & - \\
\hline
\end{tabular}

As can be observed in Table 8, most of the interpreters felt that their proficiency in Kiswahili was GOOD and EXCELLENT. Out of the interpreters who participated in the study, 60\% of the interpreters felt that their Kiswahili was GOOD while 10\% rated their Kiswahili as EXCELLENT. However, a small number 30\% felt that they were average in Kiswahili.

All the interpreters rated their proficiency in Dholuo as GOOD and EXCELLENT. This rating was also expected since they had earlier stated that their mother-tongue was Dholuo in Table 3. It could therefore be inconceivable for them to report that they were not GOOD or EXCELLENT speakers of their mother-tongue. The fact that $40 \%$ reported that they were EXCELLENT and 60\% reported that they were GOOD indicates that they have a very vibrant mothertongue use. The high proficiency of Dholuo among court interpreters could be attributed to the fact that the regions 
where the courts are situated are predominantly Dholuo-speaking regions and hence the high level of self-rated proficiency in Dholuo. At this point it is important to note that this research aimed to assess perceived proficiency and not actual level of proficiency as audio recorded on the data on discourse in court.

The next language to be rated by the interpreters is English. Table 8 shows that the interpreters rated their English as GOOD and AVERAGE. Of the respondents who participated in the study, $80 \%$ of the interpreters rated their English as GOOD, while 20\% rated their English as AVERAGE. This result was largely expected as the interpreters could not report that their English was fair or poor. This may have been influenced by the fact that all the interpreters had undergone secondary level of education, where the medium of instruction is English. It must also be remembered that English is the official language of communication in Kenyan courts and therefore the interpreters may have wanted to show that they are proficient in the language. There may also have been a link between the self-rated proficiency in English with the demand for accurate alternation between Dholuo and English with some level of proficiency.

The frequency and percentage figures in Table 8 shows a continued vibrancy in Dholuo, Kiswahili and English, and one can deduce that the interpreters are bilinguals. Bilingualism has been defined in different ways by different scholars. Valdes and Figuera (1994) see bilingualism as a condition in which there are two language systems in one individual. In terms of competence, Lavandera (1978) explains that those who use both languages for everyday use can be differentiated from those who use only one. Valdes and Figuera (1994) further agree that it is not an easy task to provide a concrete and unambiguous definition of bilingualism. Bassnet-Mcguire (1980) notes that interpreters play a vital role as linguistic intermediaries. It is therefore imperative that persons who serve as linguistic intermediaries be not only proficient in their working languages but also cognizant of how linguistic forms are dependent for effective communication. Thus, while language is the prime factor in linguistic interchange, accurate communication is important. In keeping with the focus of this research, the interpreters can therefore be classified as bilinguals in terms of their functional ability to use more than two languages. The interpreters' bilingual skills were only observed in the legal setting, determined by their general level of alternation between the Dholuo, English and Kiswahili.

The interpreters were asked to rate their own proficiency in the three language combinations that they frequently use during interpretation. The language combinations are; Dholuo-English, Dholuo- Kiswahili, and Kiswahili-English. The proficiency level was pre-coded as, VERY PROFICIENT, PROFICIENT, AVERAGE and POOR. Table 9 illustrates how the interpreters rated their own proficiency in the language combinations that they use in court.

TABLE 9:

LANGUAGE COMBINATION PROFICIENCY

\begin{tabular}{|c|c|c|c|c|c|c|c|c|}
\hline & & & UAGE & NATIOI & NCY & & & \\
\hline & Ratin & & & & & & & \\
\hline & Very & & Profic & & Aver & & Poor & \\
\hline Language combination & Freq & Per & Freq & Per & Freq & Per & Freq & Per \\
\hline Kiswahili-English & 1 & $10 \%$ & 7 & $70 \%$ & 1 & $10 \%$ & 1 & $10 \%$ \\
\hline Dholuo-English & 3 & $30 \%$ & 5 & $50 \%$ & 2 & $20 \%$ & - & - \\
\hline Dholuo- Kiswahili & 2 & $20 \%$ & 5 & $50 \%$ & 3 & $30 \%$ & - & - \\
\hline
\end{tabular}

The Kiswahili -English language combination shows some favourable rating. A total of $80 \%$ of the respondents were both VERY PROFICIENT and PROFICIENT. Another10\% was AVERAGE while another $10 \%$ were POOR. It is worth noting that both the languages are designated official language of communication in court and thus to have $20 \%$ of respondents both AVERAGE and POOR shows that they cannot communicated proficiently in the official languages of the court.

In the case of Dholuo - English, the interpreters felt that their command of Dholuo-English combination was proficient. A total of $30 \%$ of the interpreters reported VERY PROFICIENT and 50\% reported PROFICIENT. This selfrated proficiency when compared to the rate of proficiency in individual languages as shown in Table 8 suggests that the interpreters were reliable in assessing their proficiency. For example, in terms of proficiency in Dholuo $60 \%$ of the interpreters rated themselves as GOOD while 40\% rated themselves as EXCELLENT. The interpreters therefore rated their proficiency at a high level due to the nature of their duty, that of alternating from one language to another, which calls for a high level of proficiency to communicate with both parties.

The results in Table 9 indicate that the respondents felt that they had a high level of proficiency in the language combination of Dholuo-Kiswahili. A total number of $70 \%$ rated themselves both VERY PROFICIENT and PROFICIENT. There might very well be a link between this perceived proficiency and the use of Kiswahili as one of the official languages of courtroom communication.

The results of the self-rated language combination proficiency show that most of the interpreters are proficient in the three languages that were used in communication in court as follows: Dholuo-English $80 \%$ both VERY PROFICIENT and PROFICIENT, Dholuo-Kiswahili 70\% VERY PROFICIENT and PROFICIENT, Kiswahili-English $80 \%$ VERY PROFICIENT and PROFICIENT.

It is , however, important to note that in such questions that require the respondents to rate their own proficiency, the respondents might well have rated themselves higher for every language combination because they would like to be seen as proficient interpreters rather than what they really are. For the purposes of this study, we know that we are dealing with interpreters who may want to be proficient in the two official languages of the subordinate court, English and Kiswahili and their mother-tongue, Dholuo. 
Bassnet-Mcguire (1980) notes that bilingualism or fluency in two languages is a pertinent issue in interpretation. He further notes that in legal setting, the interpreters must be aware of the different legal systems of the countries where the source and target languages are spoken. This makes them appreciate fully the diverse and complex tasks that they face.

The interpreters were asked to state the languages they frequently used in court. This item was important as it showed the need for interpretation in court. The rating used was pre-coded as OFTEN, RARELY and NOT AT ALL. Table 10 below indicates how the interpreters rated the languages they frequently used in courtroom discourse.

TABLE 10:

LANGUAGES INTERPRETERS FREQUENTLY USE IN COURT

\begin{tabular}{|l|l|l|l|l|l|l|}
\hline & \multicolumn{2}{|l|}{ Rating } & Rarely & \multicolumn{2}{l|}{ Not at all } \\
\cline { 2 - 7 } & Often & Percentage & Frequency & Percentage & Frequency & Percentage \\
\hline Language & Frequency & $90 \%$ & 1 & $10 \%$ & - & - \\
\hline English & 9 & $100 \%$ & - & - & - & - \\
\hline Dholuo & 10 & $90 \%$ & 1 & $10 \%$ & - & - \\
\hline Kiswahili & 9 & & & - \\
\hline
\end{tabular}

In the case of Dholuo, the OFTEN category was rated as the highest (100\%) by the interpreters. This result is consistent with the fact that the study took place in a predominantly Dholuo-speaking region of Nyanza. The $0 \%$ for the RARELY and NOT AT ALL options is also consistent with the findings in Table 3 where all the interpreters reported that their mother tongue is Dholuo.

When the frequency and percentage of Kiswahili was worked out to illustrate the category with the highest rating, the OFTEN category attained the highest percentage with $90 \%$. However, the majority strength for Kiswahili was lower than Dholuo. This can be attributed to the fact that most of the litigants in criminal cases prefer to use Dholuo and it is only natural to expect the interpreters to use Dholuo more regularly. It is also significant to note that a small minority $(10 \%)$ used Kiswahili rarely. This means that Kiswahili was used by a majority of interpreters in courts.

In the case of English, the interpreters rated their frequency of language use as follows; the OFTEN category was the highest with $90 \%$ of the interpreters indicating that they did use English in courts. In addition $10 \%$ of the interpreters had the RARELY category. This is a departure from the norm as the official language policy is the use of English and Kiswahili in the subordinate courts. But because this item expected the respondents to rate the frequently used language in court by the interpreters, it is interesting to have $10 \%$ of interpreters not using English. This finding which shows that a minority of the interpreters rarely use English indicates that the designation of language use in subordinate courts as English and Kiswahili by court officials is important.

The interpreters were asked to rate the languages frequently used by the litigants. The ratings were pre-coded in the questionnaire under three categories: FREQUENTLY, SOMETIMES and RARELY in order to describe the frequency of the use of Dholuo, Kiswahili and English in courts. The analysis in Table 11 focuses on the frequency of language use which is expressed on the ratings given.

TABLE 11:

LANGUAGES FREQUENTLY USED BY LITIGANTS

\begin{tabular}{|l|l|l|l|l|l|l|}
\hline & \multicolumn{2}{|l|}{ Rating } & Rometimes & \multicolumn{2}{l|}{ Rarely } \\
\cline { 2 - 7 } & Frequently & Percentage & Frequency & Percentage & Frequency & Percentage \\
\hline Language & Frequency & $30 \%$ & 3 & $30 \%$ & 4 & - \\
\hline English & 3 & $90 \%$ & 1 & $10 \%$ & - & $40 \%$ \\
\hline Dholuo & 9 & $20 \%$ & 4 & $40 \%$ & 4 & $40 \%$ \\
\hline Kiswahili & 2 & 4 & & - \\
\hline
\end{tabular}

In the case of Dholuo as shown in Table 11, the FREQUENTLY category was rated the highest with $90 \%$ of the interpreters stating that they frequently use Dholuo. This result is consistent with the fact that the study took place in a predominantly Dholuo- speaking area. This high percentage of Dholuo speakers in court also serves as a pointer for the need for interpreters. The interpreters therefore have their work cut out for them as most of the legal personnel prefer to use English in courtroom communication.

The interpreters were also asked to rate the litigants' use of Kiswahili. A total of $40 \%$ of the interpreters rated the litigants' use of Kiswahili as RARELY; while FREQUENTLY and SOMETIMES were rated as $20 \%$ and $40 \%$ respectively. This is an indication that Kiswahili is not a language of choice for most litigants compared to Dholuo where $90 \%$ of the litigants were rated as FREQUENTLY use Dholuo.

In the case of the litigants use of English RARELY topped the rating given with $40 \%$ and FREQUENTLY and SOMETIMES at $30 \%$ and $30 \%$ respectively. This indicates that the litigants rarely use English which is the official language of courtroom communication.

From Table 11 it can be concluded that the majority of litigants would prefer to use Dholuo in communication in courts. This is shown by the huge percentage $(90 \%)$ of the litigants who use Dholuo in courtroom discourse. The language use background of litigants as well as those of interpreters can therefore, be said to be concordant. The finding of language frequently used by litigants indicate that a significant number of litigants come to court and do not want to use English. As one of the key variables which function as input to communication in the court, language is shown to influence the need for interpretation which in turn affects the participation in on-going discourse by the litigants. 
As Table 11 shows, Dholuo is the main language used by litigants during courtroom communication. In most cases therefore, the litigants had to use the services of interpreters. This clearly marked the need for interpreters to understand Dholuo as the language of the litigants. These frequency and percentage in Table 11 of Dholuo speaking litigants indicate that a significant population would require the assistance of an interpreter if they were to appear in court as litigants and therefore the interpreters take care of the language rights of the Dholuo speaking litigants.

The frequency and percentage in Table 11 also indicate that many litigants interact with the criminal justice system as non-English speakers. The litigants cannot therefore, participate in their own trials except via interpreters. In the justice field, language barriers can adversely affect victims. Thus, when the litigants cannot communicate in court because of language barriers, the government should provide language access plan, through the provision of interpreters.

A very central area that was identified in language use in court was the language use with the legal professionals. This aspect was relevant to us as the question of which language to use with the legal professionals is important. This question must be seen in connection with the language policy on the one hand and the language use with litigants on the other hand. The two official languages used in court are English and Kiswahili. It was therefore important to assess the language the interpreters use with the legal professionals. This is also compounded with the fact that a majority of litigants use Dholuo in court.

The interpreters were asked the language they preferred to use with the legal professionals. The legal professionals in this category were classified as Magistrates, advocates and prosecutors. The purpose of this question was to assess the interpreters preferred language with the legal professionals and to show the language use pattern with the legal professionals. The statistical analysis of the interpreters answers to this question show a varied use of language with the legal professionals. The rating provided for in this question was HIGHLY PREFERED, PREFERED, and LESS PREFERED.

Table 12 shows the language use with the magistrates. In this table, the language most interpreters prefer to use with the magistrates is English. A total of $70 \%$ of the interpreters rated their language use with the magistrate as HIGHLY PREFERRED with regards to the use of English with another 30\% rated PREFERRED in the use English with the magistrates. As noted earlier, English is the predominant language for the legal professionals. The interpreters either see the need to identify with the magistrates' language for the prestige it accords them or it is because English is the language the magistrates use and therefore the interpreters have no option other than using it. It may also be so because most of the court records and correspondence are done in English.

TABLE 12:

PREFERRED LANGUAGE USE WITH MAGISTRATES

\begin{tabular}{|l|l|l|l|l|l|l|}
\hline \multirow{2}{*}{} & \multicolumn{2}{|l|}{ Preference } & Preferred & \multicolumn{3}{l|}{ Less Preferred } \\
\cline { 2 - 7 } & Highly Preferred & Percentage & Frequency & Percentage & Frequency & Percentage \\
\hline Language & Frequency & $70 \%$ & 3 & $30 \%$ & 0 & $0 \%$ \\
\hline English & 7 & $0 \%$ & 0 & $0 \%$ & 10 & 7 \\
\hline Dholuo & 0 & $0 \%$ & 3 & $30 \%$ & 700 & 70 \\
\hline Kiswahili & 0 & & & $70 \%$ \\
\hline
\end{tabular}

The interpreters were also asked to state the language they preferred to use with the advocates. As shown in Table 13 a majority of the interpreters $(90 \%)$ returned a verdict of HIGHLY PREFERRED to use English. A total of $10 \%$ returned PREFERRED category in the use English. In the use of Kiswahili, 20\% rated PREFERRED while $80 \%$ fell on the LESS PREFERRED use of Kiswahili. None of the interpreters preferred to use Dholuo with the advocates.

TABLE 13:

PREFERRED LANGUAGE USE WITH ADVOCATES

\begin{tabular}{|l|l|l|l|l|l|l|}
\hline & \multicolumn{2}{|l|}{ Preference } & Less Preferred \\
\cline { 2 - 7 } & Highly Preferred & Preferred & Percentage & Frequency \\
\hline Language & Frequency & Percentage & Frequency & $10 \%$ & 0 & $0 \%$ \\
\hline English & 9 & $90 \%$ & 1 & $0 \%$ & 10 & $0 \%$ \\
\hline Dholuo & 0 & $0 \%$ & 0 & $20 \%$ & $100 \%$ & $80 \%$ \\
\hline Kiswahili & 0 & $0 \%$ & 20 & 0 & 8 \\
\hline
\end{tabular}

In the case of language use with the prosecutors, as shown in Table 14 below, the interpreters reported that $80 \%$ of them HIGHLY PREFERRED to use Kiswahili while 20\% PREFERRED to use Kiswahili. There were only $10 \%$ who HIGHLY PREFERRED to use English as 20\% PREFERRED to use English. A total of $70 \%$ of the interpreters reported that English was a less preferred used language with the prosecutors. All the interpreters (100\%) reported that they less preferred to use Dholuo with the prosecutors. This is in opposition to language use with the magistrates and advocates where the interpreters reported that they preferred to use English. As for the use of Kiswahili in interaction with the prosecutors, it can be speculated that the prosecutors are not trained as lawyers but are policemen. It is also common knowledge that policemen prefer to use Kiswahili to English. One of the interpreters placed a rider on the questionnaire stating that the prosecutors are policemen and that the language they mostly speak is Kiswahili. From this caveat by the interpreter, it can be assumed that policemen prefer to use Kiswahili to English. 
TABLE 14:

PREFERRED LANGUAGE USE WITH PROSECUTORS

\begin{tabular}{|l|l|l|l|l|l|l|}
\hline & \multicolumn{2}{|l|}{ Preference } & \multicolumn{2}{l|}{ Less Preferred } \\
\cline { 2 - 7 } & Highly Preferred & Preferred & Percentage & Frequency & Percentage \\
\hline Language & Frequency & Percentage & Frequency & $20 \%$ & 7 & $70 \%$ \\
\hline English & 1 & $10 \%$ & 2 & $0 \%$ & 10 & $100 \%$ \\
\hline Dholuo & 0 & $0 \%$ & 0 & $20 \%$ & 0 & $0 \%$ \\
\hline Kiswahili & 8 & $80 \%$ & 2 & & 0 \\
\hline
\end{tabular}

From this section, a number of conclusions can be reached about language use in court by the interpreters, litigants and the legal professionals. Firstly, the interpreters were asked to rate their proficiency in languages in two forms: individual language proficiency and language combination proficiency. From Table 8, it can be deduced that all the interpreters are either excellent or good speakers of Dholuo. This was a reliable response since they had also indicated earlier, in Table 3, that they are Dholuo speakers. The interpreters also rated themselves as either GOOD or AVERAGE speaker of English and Kiswahili.

In terms of their language combination proficiency, the interpreters rated their Dholuo-English language proficiency at 30\% VERY PROFICIENT and 50\%PROFICIENT. This result can be accounted for by the fact that the courts in which the research was carried out was predominantly in Dholuo speaking areas. Given that the legal professionals prefer to use English in court, the Dholuo- English language combination is, therefore, naturally the most frequent language combination used. This result is reflected in Table 9. The interpreters rated the use of Dholuo by the litigants as frequent. This result shows that the litigants tend to speak their mother tongues in court. This also serves as the basis for the provision of the interpreters in court.

Regarding language use with the legal professionals, all the interpreters reported that they use English in their discourse with the magistrates and advocates and Kiswahili with the prosecutors. It could be argued that the main reason for this dichotomy in the use of language between the magistrate and advocates on one side and the prosecutors on the other side is because the prosecutors are not trained professionals in legal matters but are policemen whereas the magistrates and advocates are trained legal professionals. In addition, in the discourse between the interpreters on one side and the magistrates and advocates on another side, it is the magistrates and advocates who initiate the conversation and they have the inclination of using the official language of the court which is English.

Courtroom discourse and interaction are defined by a person's status in court: advocate, prosecutor, magistrate or litigant. Each group members use language in a very specific way and their roles are defined (Wodak 1996). The choice of language is illustrated by the rating of language use by the different discourse participants in court. That the litigants prefer to use Dholuo during courtroom communication implies that they interact with the legal system as non-English speakers. The magistrates and advocates use English because they are a group of professionals who would adhere to the requirement of using the official language of the court. Additionally, the interpreters' rating of the language use by the litigants in court conforms to some statements contained in the linguistic rights documents. Article 20, subsections 1 and 2, of the Universal Declaration of Linguistic Rights (1996) which elaborate on the rights of persons to use their mother tongue in court. This is also stated in the International Convention on the Civil and Political Rights (1969) document and the Framework Convention for the Protection of National Minorities (1995).

\section{CONCLUSION}

This paper has presented language use issues in subordinate courts in Nyanza province, Kenya.

From data presented, a number of conclusions can be reached about language use in court by the interpreters, litigants and the legal professionals. Firstly, the interpreters were asked to rate their proficiency in languages in two forms: individual language proficiency and language combination proficiency. It can be deduced that all the interpreters are either excellent or good speakers of Dholuo. This was a reliable response since they had also indicated earlier, in Table 3, that they are Dholuo speakers. The interpreters also rated themselves as either GOOD or AVERAGE speaker of English and Kiswahili.

In terms of their language combination proficiency, the interpreters rated their Dholuo-English language proficiency at 30\% VERY PROFICIENT and 50\%PROFICIENT. This result can be accounted for by the fact that the courts in which the research was carried out are predominantly in Dholuo speaking areas. Given that the legal professionals prefer to use English in court, the Dholuo- English language combination is, therefore, naturally the most frequent language combination used. The interpreters rated the use of Dholuo by the litigants as frequent. This result shows that the litigants tend to speak their mother tongues in court. This also serves as the basis for the provision of the interpreters in court.

All the interpreters reported that they use English in their discourse with the magistrates and advocates and Kiswahili with the prosecutors. It could be argued that the main reason for this dichotomy in the use of language between the magistrate and advocates on one side and the prosecutors on the other side is because the prosecutors are not trained professionals in legal matters but are policemen whereas the magistrates and advocates are trained legal professionals. In addition, in the discourse between the interpreters on one side and the magistrates and advocates on another side, it is 
the magistrates and advocates who initiate the conversation and they have the inclination of using the official language of the court which is English.

Language use in courts is an essential component in the provision of justice. That the interpreters who participated in this study are proficient in the three languages - English, Kiswahili and Dholuo - is also important in the process of communication in courtroom discourse. But the fact that they are not trained as court interpreters is an impediment to their work. An interpreter training programme may be required for the interpreters in order for them to improve their technical and linguistic skills.

\section{REFERENCES}

[1] Bassnet-Mcguire,S. (1980). Translation Studies. New York: Methuen.

[2] Berk-Seligson, S. (1990/2002). The Bilingual Courtroom; Court Interpreters in the Judicial System. Chicago: University of Chicago Press.

[3] Gonzalez, R., Vasquez, V., and Mikkelson, H. (1991). Fundamentals of court Interpretation: Theory, Policy and Practice. Durham, North Carolina: Carolina Academic Press.

[4] Kinyanjui, K. (2000). How Our Court Works: The Administrative Practice of Kenyan Courts. Nairobi: Transafrica Press.

[5] Lavandera, B.A. (1978). The variable Component in Bilingual Performance. In J.E. Alatis (Ed), Georgetown University roundtable in Languages and Linguistics pp 391 - 409 Washington, DC. Georgetown University Press.

[6] Mbaabu, I. (1996). Language Policy in East Africa: A Dependency Theory Perspective. Nairobi. Educational Research Publications.

[7] Mikkelson, H. (2000). Introduction to Court Interpreting. Manchester \& Northampton: St Jerome Publishing.

[8] Mikkelson, H. (1998). Towards the Redefinition of the Role of the Court Interpreter. In Interpreting Vol. 3 (1) Pg 21 - 45.

[9] Penman, R. (1990). Faceworks and Politeness: Multiple Goals in Courtroom Discourse. In Tracy, K and Coupland, N. (eds) Multiple Goals in Discourse. Clevedon: Multilingual Matters.

[10] Valdes, G. and Figuera, R.A. (1994). Bilingualism and Testing: A Special Case of Bias. Norwood, N.J: Ablex.

[11] Wodak, R. (1996). Disorders of Discourse. London: Longman.

Kenneth Odhiambo holds a $\mathrm{PhD}$ in Linguistics from Maseno University, Kenya. He also has a Master of Philosophy in Linguistics and Bachelor of Education from Moi University. He is currently a Lecturer in the Department of Social Sciences at University of Kabianga. Dr. Odhiambo's research interests are in discourse in courtroom, courtroom interpretation, language rights and sociolinguistics.

Claris Kasamba Kavulani has a Master of Philosophy in Communication Studies from Moi University in Kenya. She also holds a Bachelor of Education (Arts) degree from the same university. She is a specialist in communication. She currently works as an administrator in the Public Relations Office at the University of Kabianga which is in Kericho County -Kenya.

Peter Maina Matu, PhD is an Associate Professor in Linguistics and Communication and Director of Common Undergraduate Courses at Technical University of Kenya. He has published widely in both local and international journals. His research interests are centred on syntax, pragmatics, communication, media and discourse studies. 